\title{
Causes and Incidence of Rape among Middle Age and Young Adult in Lagos State, Nigeria
}

\author{
${ }^{1}$ T.O. Peters and ${ }^{2} \mathrm{O} . \mathrm{W}$. Olowa \\ ${ }^{1}$ National Open University of Nigeria, Ahmadu Bello Way, Victoria Island, Lagos, Nigeria \\ ${ }^{2}$ Federal College of Education (Technical) Akoka, Lagos, Nigeria
}

\begin{abstract}
The study examined the cause and incidence of rape amongst middle age and young adult in Ojodu, a border town between Lagos and Ogun states. Rape can be defined in various ways but in most jurisdiction, it is defined as sexual intercourse or other forms of sexual penetration by one person (the accused) with or against another person (the victim) without the consent of the victim. A total of 100 respondents were systematically selected for this study and with the use of simple descriptive technique analysed. The outcome revealed that there are incidences of rape within the society which many said is criminal. There are strong indications that socio-cultural factors are part of the contributing factors. It recommended among other thing that perpetrators should be punished and victims should be well supported.
\end{abstract}

Key words: Rape, Lagos, victims, sex, immoral, women, Nigeria

\section{INTRODUCTION}

Universally, rape is considered to be an immoral act which is not peculiar to any nation, race, creed or gender. It is a non consensual, forcible sexual relation or other sexual activity. It is an unwanted sexual intercourse which need not be full penetration but may involve only contact between the genitals.

Study by Cohen and Seghorn in 2006 suggested four classifications of rapists which other researchers supported, this includes:

- Displaced aggression

- Impulse

- Sex aggression diffusion and

- Compensation

All these have their specific characteristic. By displaced aggression, they mean the rape that is committed to physically harm the victim who is usually a stranger. The perpetrator uses rape as an outlet for his anger which almost always follows some unpleasant event involving him and his wife, girl friend or mother. Impulse rape is based on impulse and is not motivated by sexual hunger or feelings. For example, a rape that is carried out during a dacoity or robbery. Sex aggression diffusion is the one in which the rapist is aroused by aggressive thought as the aggressive and sexual components coexist. The perpetrator sees the victims struggle as seductive and even believes that women like to be raped. In compensation, the key component is sex and if the victim struggles or tries to escape, he would be rapist flees. The recurrent fantasy of the rapist is that the victim will yield. The rapist is passive and the act is mostly pre planned. Rape can be committed against a minor who is legally incapable of consent, a mentally impaired or an unconscious person. Research demonstrates that most rape victims are female and 9\% male with $99 \%$ of the offenders being males (Whatley, 2005). There are several types of rape amongst which are date rape, gang rape, acquaintance rape, war rape and statutory rape. Rape is not always done for sexual satisfaction of the perpetrator. Blackmail, punishment, curiosity, money and power are all motives for rape as well as sex.

In this society, rape is attached to stigmatization, this is the major reason for low report of rape incidence while the criminal prosecution of rape cases involves the willingness of the victim and ability to report and describe a rape. Biologically evidence such as semen, blood, vaginal secretions and epithelia cells, saliva, etc., are typically collected by rape kit, culture are obtained for analysis of sexually transmitted infections, HIV screening is done and same is repeated in 3-6 months.

Physical and psychological trauma are the effect and aftermath of rape, the most common trauma are those related to reproductive health, i.e., gynaecological which include pregnancy, sexually transmitted infections, urinary tract infection, etc. Psychological trauma include rape trauma syndrome including self blame,

Corresponding Author: T.O. Peters, National Open University of Nigeria, Ahmadu Bello Way, Victoria Island, Lagos, Nigeria 
suicide/suicidal attempt, lowered self esteem, anxiety, eating disorders and post traumatic stress disorder. The incidence of rape varies in different parts of the world. In United States of America, cases of rape/sexual assault of about 212190 were recorded by the US Department of Justice in 2006.

In the United Kingdom according to British Broadcasting Cooperation, one ( $\mathrm{BBCl}$ )'s presentation of 12th November 2007, about 85,00 women were raped in 2006, this is about 230 cases day ${ }^{-1}$ and a ratio of about $1: 200$ women of the population. In Eastern Congo, the worst rape cases in the world is recorded to date. There are about 200,000 surviving rape victims living in Democratic Republic of Congo. In South Africa, the highest incidences of child and baby rape in the world with $>67,000$ cases of rape and sexual assaults against children were reported in 2000.

In Nigeria, 10,079 cases of rape were reported between 2001-2005, the affected females are usually between the ages of 16-45 years, this may be an underestimate since, about $18 \%$ of rape victims actually report to police. The high incidence of rape is a precursor for the spread of HIV and AIDS. Studies like this is important to create more awareness and evolve ideas and policies towards stemming, the danger posed by this vices to the society. With high incidence of rape, HIV and AIDS is bound to spread like wild fire and consume more people who are of the working age and thus devastate the economy.

While much is known and have been studied about causes and incidence of rape in other climes much that is known about rape in Nigeria are anecdotal rather than empirical. In the light of this, the study will critically analyze the rape incidences among men in the middle age and young adult in Lagos using Ojodu area, a border town known for bubbling economic activities as a case study. To this ends, this study will strive to provide answer to the following questions:

- How much do men of middle age and young adults know about rape?

- What are those factors contributing to rape?

- To what extent has cultural factors affects the incidence of rape among men?

- What are the aftermath or consequences of rape on the victims?

Against this background, the study is: to access the level of knowledge and awareness of rape by men of middle age and young adult; identify the causes and motives of rape among the selected age group; analyze the cultural factors contributing to rape incidences.
Operational definition: The operational definition is as follows:

Middle age: This is a long period in the life span between ages $40-60$ years. It can be early middle age, a period between $40-50$ years or advanced middle age, a period between $50-60$ years.

Rape: This is the criminal, forcible sexual intercourse without the consent of the individual.

Young men: These are male gender that fall under the age of 40 years which is early middle age or adulthood.

\section{Literature review}

Prevalence and types of rape: Recently, UNICEF commented that rape occur more on women and children in African conflict zones. It was no longer perpetrated by combatants but also by civilians. According to WHO (1997), rape is common in countries affected by wars and natural disasters, drawing a link between the occurrence of sexual violence with the significant uprooting of a society and the crumbling of the social norms.

Reported case of rape in Kenya doubled following post election conflicts. According to UNICEF, rape was prevalent in conflict zones in Sudan, Chad and the Democratic Republic of Congo, 200,000 females are living with sexual violence (rape). An estimated 500,000 women were raped during the 1994 Rwandan genocide. The International Criminal Tribunal for Rwanda found that systematic rape was used especially, against the tutsi women to destroy the ethnic group.

There are several types of rape, generally categorized by reference to the situation in which the rape occurs and also to the sex and/or characteristics of the victim or perpetrator. The victim does not have to be penetrated to be raped; objects or hand can be used by the rapist to stimulate the genitals.

The perpetrator can use drugs or hypnosis to incapacitate the victim in order to carry out his motives which may be for blackmail, punishment, curiosity, money, power and sex. Some of the types include date rape, gang rape, marital rape or spousal rape, incestual rape, child sexual abuse, prison rape, acquaintance rape, war rape and statutory rape.

Child sexual abuse: Gelder shows that the prevalence of sexual abuse from survey and criminal statistics is estimated to be $10 \%$ of child abuse. Female children are more often abused than male children, a ratio of about 2-3:1 (Finkelhor, 1985). Offenders are often male. Many sex 
abuse takes place within the family. Step fathers are also over represented among abusers (Russell, 1994). According to Gelder, said retrospective studies suggest that between $20-50 \%$ of women in population, survey recalled been abuse as a child. The survey includes wide range of experiences from minor touching to repeated intercourse.

Incestual rape: The child and the perpetrator are related biologically or by marriage. In at least $50 \%$ of cases, the rapist is the child's father or step father. The uncle, brothers, step brothers, grandfather and other male relatives (including common law relatives such as the mother's boyfriend) are also involved. Kirkwood and Cecil (2001) shows that about $75 \%$ of reported cases of sexual abuse involved father-daughter incest, many cases of sibling incest are denied by parents. They also stressed that the incestuous behavior usually begin when the daughter is 10 years old. Staffer (1998), describe the following as forms of incestrual sexual abuse:

- Involving children in pornographic activities such as posing for nude pictures or watching pornographic film for either money or favour

- Adult imploring children to touch their genitalia, thereby stimulating them

- $\quad$ Genital fondling by adult on children by touching a child inappropriately in the breast, vulva or penis while the adult derives pleasure by the act

- Involving children in oval genital relations by requesting the child to use her mouth to arouse a man's penis

- Adult inserting a finger or penis into the child's anus

Statutory rape: Harold defined it as intercourse that is harmful between an older adult and a female under the age of consent under 14 years (note that a male of 18 years and a female of 15 years may have a consensual sex. It may be non-assaultive, non violent nor is it a deviant act, unless the age discrepancy is sufficient for the man to be defined as a pedophile. Charges are pressed by the parents of the victims and not the victim (the abused girl).

War rape: Rape according to $U N I C E F$ is common in countries affected by wars. Rape in the course of war, dates back to antiquity, old enough to be mentioned in the Holy Book (Bible). The Israelite, Persian, Greek and Roman armies reportedly engaged in war rape. During the world war II, 200,000 Korean and Chinese women were forced into prostitution in Japanese military brothels and they were called comfort women. About 20,000 Bosnian
Muslim women were raped by Serb forces during the Bosnian war. It was estimated that about $60 \%$ of combatants in Congo are HIV infected.

Gang rape: This is predominantly committed by men (Bourgeois, 2006), sexual aggressiveness is often a defining characteristics of manhood in the group and is significantly related to the wish of being held in high esteem. Sexually aggressive behavior among young men has been linked with gang membership and having delinquent peers. It is been viewed by men involved and sometimes by others too as legitimate in that it is seen to discourage or punish perceived immoral behaviour among women such as wearing short skirts or frequenting bars.

Marital/spousal rape: This is a prevalent form of violence against women. It can be defined as any unwanted intercourse or penetration (vaginal, anal or oral) obtained by force or when the wife is unable to consent (Pagelow, 1992; Russell, 1994). Martial rape have included couples who are legally married separated, divorced or cohabiting with the understanding that the dynamics of sexual violence in a long term cohabiting relationship are similar to those of a married couple (Mahoney et al., 2001).

Research has shown that $10-14 \%$ of married women experience rape in marriage (Finkelhor and Y1lo, 1985). Marital or spousal rape is a common rape by intimate partner. Women who are in physically abused relationship are vulnerable to rape by their partners. Little attention is paid to this type of rape by the society even by the criminal justice system (Bergen, 2005). It was not until 1970 that society began to acknowledge that rape in marriage do occur and it is still being perceived as a lesser crime than other forms of rape within the culture as some questions are being raised as to whether it is possible to rape one's wife. (Whatley, 2005; Kirkwood and Cecil, 2001).

Prison rape: This type of rape violates international, US and state laws but it has been allowed to continue. Men, women and youth inmates are vulnerable to rape, especially 1st time offenders. Prison rape occurs most easily when no one is around to see or hear, particularly at night and in hidden areas that are difficult to monitor. Lack of vigilance and ignoring screams for help has always been the complaints of victims, overcrowding and insufficient staffing are contributory factors. Victims may be marked for future attacks and are eventually forced into long term sexual enslavement.

Women at risk are usually those that are young, mentally ill and first-time offenders. Male custodial official 
have raped prisoners and have abused their authority by exchanging goods and privileges for sex. Male prison officials are often allowed to watch female inmates when they dress up, shower or use the toilet, some female inmates are verbally degraded and harassed by correction officers.

Acquaintance rape: It is also referred to date rape and hidden rape. It started assuming damaging form in the public consciousness in the early 1980 's. In acquaintance rape, the victims are blamed more than when the perpetrators are strangers.

Classification of rape: Study by Cohen and Seghron suggested four classification of rapists, this is supported by other research as:

Motivation and theories of rape: The motives of rapist can be multi-factorial as several factors have been proposed such as anger, desire for power, sadism, sexual gratification and evolutionary pressure, socio economics, psychopathy and ethical standards. However, it is open to debate.

Socio biological theories of rape: It is the lack of informed consent that defines rape among humans, however sociologists. Thornhill and Palmer (2001) argue that the ability to understand rape and thereby prevent it is severely compromised because its basis in human evolution has been ignored. These sociologists indicate that it is an evolutionary strategy for certain male who lack the ability to persuade the female by non-violent means.

Myths theory: There are dangerous myths that can lead to rape (Burt, 1991) commonly held myths such as these contribute to date and marital rape:

- A man must have sex to prove his masculinity

- When a woman says no, she means yes, so men should ignore women's refusals

- If a woman engages in kissing or petting, she is obligated to engage in sexual intercourse

- What goes between a husband and a wife is no one else's business

- The man should be head of the household

Gender theory: Some people hold beliefs justifying rape more strongly than others. Individual differences are also important. Men who rape tend to believe more strongly in myths about rape and are more likely to engage in fantasies about coercive sex. Traditional gender roles prescribing, female submission and male dominance are linked to rape. Studies in several countries have suggested that rigid gender roles and promotion of an ideology of male toughness are related to violence against women.

Among the cause of rape is the widespread portrayal of girls and women in the media as sex objects and a climate of disrespect towards women. The feminist theory of rape is summarized by Susan Brown miller's statements: rape is nothing more or less than a conscious process of intimidation by which all men keep all women in a state of fear.

McCandle's drwe theory of sexual victimization: McCandles in Mahoney et al. (2001) proposed Drive theory of individual behavior and development. This theory was predicted on the view that all human behavior is based on drives and the direction of behavior takes a consequence of a particular drive. Over time, the individual learns that certain behavior reduce drive state while some of these behavior will likely attain rewards and the individual will eliminate or avoid those drive reducing behavior likely to result in punishment.

The relevance of this theory to men of middle age and young adult is that the direction of their behavior takes a consequence of a particular motive which has to be controlled to a socially acceptable ways. The drive inducing behavior must be avoided to appreciate other peoples' self esteem.

Factors increasing men's risk of committing rape: Universally, rape is considered to be an immoral act which is not peculiar to any nation, race, creed or gender. The prevalence of sexual violence however remains under research. Data on sexual violent men also show that most men direct their acts at women whom they already know (WHO, 1997). Among the factors, increasing the risk of a man committing rape are those related to attitudes and beliefs as well as behavior arising from situation and social conditions that provide opportunities and support for abuse.

Individual factors: Consumption of alcohol and drugs use has been shown to play a disinhibition role in certain types of (rape) sexual assault. The biological link between alcohol consumption and violence are however complex. Research on the social anthropology of alcohol consumption suggests that connections between violence, drinking and drunkenness are socially learnt rather than universal (MC Donald, 2004). 
Researchers have noted that men under the influence of alcohol are prone to impulsive and antisocial behavior. These people are more likely to act violently when drunk because they do not consider that they will be held accountable for their behavior. There's coercive sexual fantasies and other attitudes and beliefs supportive of sexual violence. There's preference for impersonal sex by such men and also history of sexual abuse as a child. Men who rape have hostility towards women and had witnessed family violence as a child.

Psychological factor: There has been considerable research in recent times on the role of cognitive variables among the set of factors that can lead to rape. Psychosexual analyst, sigmund freud, identified oedipus complex in the male, stagnation of which makes the male to be prone to having sexual problems later in life such as failure to handle competitive relationship, contributing to rape by such male. Men who sexually assault women are more likely to consider their victims responsible for their rape being less knowledgeable about the impact of rape on victims. Men who rape may misread cues given out by women in social situations and may lack inhibition that act to suppress associations between sex and aggression. They may have crave sexual fantasies, generally encouraged by access to pornography. A further association is with adversely attitudes on gender that hold that women are opponents to be challenged and conquered.

Relationship factor: Some forms of sexual violence such as gang rape are predominantly committed by men. Sexual aggressiveness is often a defining characteristic of manhood in the group and is significantly related to the wish to be held in high esteem. Sexually aggressive behavior among young men has been linked with gang membership and association with criminal gang, sexually aggressive friends, delinquent peers and having been abused as a child.

Family environment characterized by physical violence and few resources having been raised in a strongly patriarchal family having an emotionally unsupportive family environment are some of the factors contributing to rape by men such men may consider their family honour more important than the health and safety of the victim.

Community factors: Poverty is linked to both the rapist and his victim, several researchers have argued that the relationship between poverty and perpetration of sexual violence is mediated through forms of crisis of masculine identity (Marrel, 2001). Period of enforced idleness, lack of employment opportunities, discrimination between the rich and the poor, lack of institutional support from police and judicial system in time of conflict, general tolerance of sexual assault within the community of sexual violence are all contributing factors to rape by men.

Physical and social environment: The fear of rape is typically associated with being outside the home but to a certain extent rape occur in the home of the victim or perpetrator. Nonetheless, abduction is influenced by the physical environment. The social environment is more important than the physical environment considering the issue of rape, the social environment hold in high esteem its belief in male superiority, male entitlement to sex and female submission and traditional female sex role, leaving room for sexual violence against women. Also the social effect of pornography can not ne ignored.

Societal factor: There are variations in the laws and policies between countries in their approach to rape or sexual violence. Some legislation and legal procedure has a broad definition of rape that includes rape and with heavy penalties for those convicted and a strong response in supporting victim. Societal factors which increase men's risk of committing rape include societal worms supported of sexual violence, societal norms supportive of male superiority and sexual entitlement; weak laws and policies related to sexual violence and those related to gender equality.

Economic factors: Factors operating at a national level have an international dimension. Global trends such as free trade has been accompanished by an increase in the movement around the world of women and girls for labour including in the sex industry. Economic melt down followed by Economic Structure Adjustment programmes, drawn up by international agencies have accentuated poverty and unemployment thereby increasing the like hood of sexual trafficking and sexual violence.

\section{MATERIALS AND METHODS}

Study area, intrument and sampling technique: The study is non-experimental, descriptive across-sectional approach. This was adopted to study, the critical analysis of rape incidence among men of middle age and young adult in Lagos state. The target population consisted of four selected areas in Ojodu area of Lagos state. In this research, 100 subjects were selected for the purpose of the study. 
The research was carried out in Ojodu area of Lagos state. The four selected areas of study are Ojodu Berger, Isheri, Gbadamosi and Adigboluja. These areas are boundary region between Lagos and Ogun state. They fall between Ojodu local government of Lagos state and Ifo local government of Ogun state. They are densely populated. Private and public schools are located in these areas. Two local government primary health centers' are within these areas. The ever busy Lagos/Ibadan express way passes through the area. Numerous financial institutions are located in these areas with highly populated churches and mosque. These areas have both the government bus park and general motor parks. The economic activities of the people are predominantly trading as a retail market is located there also.

Systematic sampling technique $(k=N / n$ where $k$ is the sampling interval and $1 / \mathrm{k}$ is the sampling fraction) was used in selecting people that really answered the questionnaire distributed on the incidence of rape by men of middle age and young adult in Ojodu Berger, Isheri, Gbadamosi and Adigboluja communities of Ojodu area. The tool for data collection was self administered questionnaire which was given out to respondents. The questionnaire consist of two sections namely biographical and knowledge of contributing factors. Consent of the participant was sought and due explanation was offered to clarify doubt and confirm anonymity before the self administered questionnaire was given out. Fortunately for us, we were able to retrieve, 100 questionaieres given even though it was tedious exercise due ethical issues involved.

Data analysis: Data was analyzed using descriptive statistics such as frequencies, percentages, tables and charts.

\section{RESULTS AND DISCUSSION}

Table 1 and 2 showed that majority of the respondents (about 65\%) fall between the middle age bracket, male, married and had tertiary education. Distribution by ty of marriage revealed that respondents were mostly polygamists and lived in either self-contain apartment or flats. Generally, by experience living in one or what is known as tenement building in this part of the world is known to gender rape or its tendencies due to congestion and poverty status of most residents. Thus responses in 2nd part of the questionnaire are most likely to exhibit less biases. From Table 3, breakdown analysis was carried out as follows to show the awareness, possible causes and outcomes of rapes as perceived by our respondent.
Table 1: Sampling proportion

\begin{tabular}{llcc}
\hline Location & Male & Female & Sample size \\
\hline Adigboluja & 15 & 10 & 25 \\
Gbadamosi & 18 & 7 & 25 \\
Isheri & 14 & 11 & 25 \\
Ojodu Berger & 16 & 37 & 25 \\
Total & 63 & 37 & 100 \\
\hline
\end{tabular}

Table 2: Demographic data of respondents

\begin{tabular}{lrr} 
Variables & No. of respondent & Percentage \\
\hline Age distribution of respondents (years) & & \\
$30-35$ & 28 & 28 \\
$36-40$ & 37 & 35 \\
41 and above & 35 & 35 \\
Total & 100 & 100 \\
Marital status & & \\
Single & 16 & 16 \\
Married & 68 & 68 \\
Divorced & 10 & 10 \\
Widowed & 6 & 6 \\
Total & 100 & 100 \\
Educational status & & \\
None & 4 & 4 \\
Primary & 12 & 12 \\
Secondary & 31 & 31 \\
Tertiary & 53 & 53 \\
Total & 100 & 100 \\
Sex of respondents & & \\
Male & 72 & 72 \\
Female & 28 & 28 \\
Total & 100 & 100 \\
Type of family & & \\
Monogamy & 64 & 64 \\
Polygamy & 36 & 36 \\
Total & 100 & 100 \\
Type of accomodation & & \\
A room & 20 & 20 \\
Self contain & 32 & 32 \\
Flat & 46 & 46 \\
Duplex & 2 & 100 \\
Total & 100 & \\
\hline & & \\
\hline
\end{tabular}

Table 3: Responses of 100 respondents to questionnaire in percentages

\begin{tabular}{lrr}
\hline Questions & Yes & No \\
Have you heard of sexual abuse or rape? & 84 & 16 \\
Do you know rape is a criminal offence? & 66 & 34 \\
Can rape be used as punishment on the females & 56 & 44 \\
Is alcoholism a contributing factor to rape? & 78 & 22 \\
Have you ever been abused as a child? & 10 & 90 \\
Can rape result in pregnancy? & 92 & 18 \\
Do you believe that reading of pomographic? & 75 & 25 \\
Magazines Influence men to rape? & 88 & 12 \\
Can a father rape his own daughter(s)? & 70 & 30 \\
Can indecent dressing by females influence men to rape? & 72 & 28 \\
Does rape lead to stigmatization in the society? & 41 & 59 \\
Is it true that when women say no to sex, it really & & \\
means yes? & 86 & 14 \\
Can rape lead to contact of sexually transmitted & & \\
infection and HIV? & 60 & 40 \\
Do you believe in female submission? & 84 & 16 \\
Is a woman within the cultural context allowed to & & \\
refuse her man's sexual need? & 65 & 35 \\
Do you believe in male dominance? & 95 & 5 \\
Do you think watching live sex shows or female nude & & \\
dancers aid rape? & & 10 \\
Can rape be prevented? & 90 & \\
Should a rapist be punished? &
\end{tabular}


Table 4: Level of awareness of respondents on the incidences of rape

Responses

Respondents have heard about rape

Respondents know rape is criminal

Respondents believe fathers can rape their daughters Prcentage

84

66

88

Table 5: Knowledge of respondents on the individual factors contributing

Responses to rape

Alcoholism

Pornography

Indecent dressing of females

Life sex shows/nude dancers

Rape as a punishment for female Percentage

78

75

70

56

Table 6: Influence of cultural factors contributing to rape

\begin{tabular}{lc}
\hline Responses & Percentage \\
Male dominance & 65 \\
Culture of non-refusal & 84 \\
Female submission of sex by wives to their husbands & 60 \\
\hline
\end{tabular}

Table 7: Response of respondents on the possible outcome of rape

\begin{tabular}{lc}
\hline Responses & Percentage \\
\hline Pregnancy & 92 \\
Sexually transmitted infection/HIV/AIDS & 90 \\
Punishment for rapists & 98 \\
Stigmatization & 78 \\
\hline
\end{tabular}

Majority of respondents are aware of rape and sexual abuse, believe rape is criminal and that fathers can rape their daughters (Table 4 and 5). Similarly, majority also succumb to the fact that alcoholism, watching of pornographic magazines and movies, indecent dressing by the female, watching of sex shows and nude dancers attract men to rape while just about $56 \%$ indicated that men rape to punish the female (Table 6).

Male dominance as a cultural factor contributing to rape, the culture of none-refusal of sex by wives to their husbands is a factor and female submission are overwhelmingly believed by majority contributing factor to incidence of rape. Table 7. Pregnancy, sexually transmitted infection and $\mathrm{HIV}$ and stigmatization are possible outcome of rape. However, almost respondents indicated that rapist should be punished.

\section{CONCLUSION}

The analysis of the survey showed that there are more male respondents than female on the study. Many of the respondents are aware of the incidences of rape and that some fathers can rape their daughters. It was gathered that some factors including socio-cultural and individual are contributing to rape. The aftermath of rape is not pleasant as pregnancy may occur, contact of infections and also stigmatization of the victim by the general society are possible. By implication, the study will enable, the nurses at Emergency Department (ED) especially the Sexual Assault Nurse Examiners (SANE) to know the importance of their roles in the care and management of the patient and the precautions to be taken in the collection of evidences which may be needed for legal proceedings.

\section{RECOMMENDATIONS}

Nurses as educators should be able to teach the victims and their families/relatives, the effective strategies for preventing rape and improving sexual communication. Nurses as care givers should be able to assist the patient in the restoration of her self esteem following the consequences of rape such as rape trauma syndrome amongst others. It is therefore recommended as follows:

- Focus more attention on organization of seminars; campaign, talk shows, etc.s on the need for decent dressings among the female gender by $\mathrm{NGO}$, the media and the government

- Care providers should be empowered to report cases of rape to the law enforcement bodies without any consideration to the perpetrators personality. perpetrators should be punished

- Government should provide a safe environment that is free of deviants by creating employment and discouraging the sex industry

- The society should create an enabling environment for gender equality to erase the idea of female submission and male supremacy

\section{REFERENCES}

Bergen, R.K., 2005. Wife Rape: Understanding the Response of Survivors and Service Providers. Thousand Oaks, CA Sage.

Bourgeois, P., 2006. In Search of Respect. Free press, New York.

Burt, M., 1991. Cultural myths and support for rape. J. Personal Soc. Psychol., 38: 217-230.

Finkelhor, D. and K. Y1lo, 1985. License to Rape: Sexual Abuse of Wives. Holt, Rine hart, and Winston, New York.

Finkelhor, D., 1985. Child Sexual Abuse: New Theory and Research. Free Press, New York.

Kirkwood, M.K. and D.K. Cecil, 2001. A student assessment of rape laws and marital exemption, violence against women's risk and women's health. Violence Against Women, 5: 1017-1035.

MC Donald, M., 2004. Gender, Drunks and Drugs. Oxford Berge Publish, UK. 
Mahoney, P., L. Williams and C.M. West, 2001. Violence Against Women by Intimate Relationship Partnership. Thousand Oaks, Sage, CA.

Marrel, R., 2001. Changing Men in Southern Africa. University of National Press, Pieter Maritzburg.

Pagelow, M.D., 1992. Adult victims of domestic violence. J. Interpersonal Violence, 7: 87-120.

Russell, D.E.H., 1994. Against pornography: The evidence of harm. Russell Publications, Berkeley.

Staffer, C.D., 1998. Psychiatry for Students. Academic press, USA.
Thornhill, R. and C.T. Palmer, 2001. A Natural History of Rape: Biological Bases of Sexual Coercion. MIT Press, Cambridge.

WHO, 1997. Violence Against Women: A Priority Health Issue. Document WHO FRH/WHD/197.8, World Health Organization, Geneva.

Whatley, M.A., 2005. The effect of participant sex, victim dress and traditional attitude on causal judgments for marital rape victim. J. Family Violence, 20: 191-200. 